\title{
Mechanism Design Based on a Bargaining with a Risk of Breakdown: Application to Commodity Import and Export of China
}

\author{
Xue-Feng ZHANG $^{1}$
}

\author{
School of Economics and Management, North China University of Technology, \\ Beijing 100144, China
}

Keywords: Mechanism design, Risk of breakdown, Bargaining, Passiveness.

\begin{abstract}
This paper established a dynamic bargaining model of international commodity transfer, and analyzed the change of equilibrium in the effect of discount factor and risk of breakdown. According to the improvement of subjective probability with a risk of breakdown, there existed a unique Sub-game Perfect Nash Equilibrium (SPNE). At the same time, we discuss the application to improve the passivity in China trade using this balanced concept of SPNE. The result shows some conclusions. Firstly, the patience in bargaining may lead to more expected return. Secondly, the allocation of profit in the equilibrium depends on the difference among discount rate, subjective probability of the breakdown risk and the breakdown point. Thirdly, the price in equilibrium will higher, if the provider of commodity pay more attention to his subjective probability and depend on his subjective probability.
\end{abstract}

\section{Introduction}

The trade of commodities between countries is increasing with the boom of international economy. There are potential risks in international trade which has complex rules and many procedures. Especially the negotiation before contract is crucial to the success of business. Normally, a complete product negotiation consists of five sections. The first part is a detailed investigation of the commodity and company. The second part is enquiry. The third part is information exchange and selection of the object of negotiations. The fourth part is technical negotiations. The fifth part Business negotiations. The development of Chinese economy and foreign trade has shown Chinese economy strength, but still, there are many problems need to be solved. First of all, China is weak in independent R\&D and lack of autonomous intellectual property rights and technological innovation, which decreased the economic benefit. Advocating the export of high-tech products will improve this situation. Secondly, because the discourse power is hold by some other countries and China has been treated specially (e.g. the limits set for China), the risk of breakdown during the foreign trade negotiation for China has been increased.

Generally, in order to get more payoffs, both parties involved in a bargaining will try to get more information before making an offer or a counteroffer. Rubinstein[1] establishes an original non-cooperative bargaining model. Houba and Bolt [2] generalized their ideas and summarizes the practical application of bargaining models in real negotiation. Assumptions of Rubinstein's model are as follows: time unlimited, complete information and rotating offer. It established the existence of SPNE in bargaining models and it was Pareto efficient. Christopher Avery and Peter B.Zemsky[3]showed the concept of "money burning". If the treat is credible, then the SPNE will be broken down by "money burning". During a dynamic game of negotiations, time is a non-ignorable factor which is the substance of delay.

The concept of "risk of breakdown" was first proposed when Binmore and Rubinstein were studying the bargaining problem. Osborne and Rubinstein[4]did a further exploration in their research of market. Muthoo[5]combined discounting factor and risk of breakdown in a model. As Rubinstein stated in his model, we assume the participant offers first. Denoting the final share of the participant $i$ and $j$ as $\mu_{i}$ and $\mu_{j}, x_{i}$ and $x_{j}$ represent final payoffs of $i$ and $j$. Hence, the final respective share of the pie as follows: 


$$
\begin{gathered}
\text { Eq.1 } x_{i}=\pi\left(1-\delta_{j}\right) /\left(1-\delta_{i} \delta_{j}\right) \\
\text { Eq.2 } x_{j}=\pi \delta_{j}\left(1-\delta_{i}\right) /\left(1-\delta_{i} \delta_{j}\right)
\end{gathered}
$$

$\delta_{i}$ and $\delta_{j}$ is the discount factor of the participants $i$ and $j$,besides, $\delta_{i}=e^{r_{i} \Delta} \quad$ ( $r_{i}$ is the discounting rate), $\pi$ is the expected revenue.

Corominas-Bosch [6]discussed bargaining process in his paper but assigned the formulas (1) and (2) directly but fail to give a more detailed explanation. Muthoo[7]argued the risks of breakdown can be attributed to as follows: Firstly, the most important is external options. Because of factor competition, one of the participants made a deal with any competitor $j^{*}$ of $j$. As a result, the negotiation broke down. Secondly because of the change of external condition, the interests of cooperation disappeared, so there was no ground for a negotiation. For example, when two parties are bargaining over a distribution of the return of a new technology, there is a better one been invented by another company and the former technology outmoded. Thirdly that is stochastic factor. The patience of a participant would change over time and consequently, to terminate the negotiations and find another partner. Any of the above will lead to a breakdown. Fraja and Muthoo ${ }^{[8]}$ approximated the probabilities of the happening of the factor that will lead to the breakdown as a function which submits to the Poisson distribution which parameter is $\lambda(\lambda>0)$.

The parameter $k$ is a non-negative integer, denoting the average happening times of the breakdown factors as $\lambda$. Any happening of the breakdown factor can result in breakdown. Statistically, when the happening of breakdown factors submits to the Poisson distribution which parameter is $\lambda(\lambda>0)$.

Colesand Muthoo ${ }^{[9]}$ demonstrated that in a free competitive market, the key influencing factor is competition when there is a bargaining between $i$ and $j$. As for $i$, competitor $j^{*}$ of $j$ may reach an agreement with $i$ and the quantity of $j^{*}$ is in average $\lambda_{i}$ per period $\Delta$ after any nodes $t \Delta$. Naturally, the contract from the negotiation and unavoidably the negotiation may be break down. Muthoo argues that the subjective probability is different between two parties.

Wolinsky [10]argued that in the process of rotating bargaining, it could be seen that the breakdown of a negotiation depends on the respective actions of the bargaining parties. As long as one party dropped out, the negotiation broken down. Hence, the situation can be divided into three categories: Firstly, participant and quit simultaneously, the negotiation breaks down; Secondly, participant or quit and the negotiation breaks down. But the counterparty still chose to wait. Thirdly , neither participant quits nor the negotiation finally reached an agreement. Both party obtained their own payoffs. Compte and Jehiel[11] argued that the end of the negotiation affected by the previous offers and concessions. Under this circumstance, the breakdown never happens, while the potential risk of breakdown exists and affects the offers and counteroffers continuously.

\section{Model}

The timing of the game is as follows: at time 0 , participant $i$ makes a proposal to $j$, if it is accepted then making a distribution according to the offer. If it is rejected, then $j$ will make a counteroffer at time $\Delta>0$. If the counteroffer is accepted by $i$. Otherwise $i$ will make a counteroffer to $j$ at time $2 \Delta$. $i$ will make a proposal to $j$ at time $t \Delta(0,2 \Delta, 4 \Delta, \cdots)$ when $t$ is an even number and the negotiation will end in an agreement if $j$ accepts it. If not, $j$ will make a counteroffer at time $(t+1) \Delta(\Delta, 3 \Delta, 5 \Delta, \cdots)$ and if the offer is accepted, the negotiation ends in an agreement. 


\section{Assumptions}

\section{Definition of Breakdown}

According to the property of the index distribution, at any time $t \Delta$, the probability of breakdown is as follows,

$$
\text { Eq.3 } P=1-e^{-\lambda \Delta}
$$

And $\lim _{\Delta \rightarrow 0} P=\lambda \Delta$.

Suppose at time $t \Delta, i$ rejects $j$ 's offer with the probability $\lambda \Delta$ then makes a counteroffer and pushes the negotiation into time $(t+1) \Delta$ with the probability $(1-\lambda \Delta)$. If the negotiation broke down due to disagreement e.g. $i$ rejected $j$ 's offer, the negotiation terminates. Suppose $j$ 's offer is $\left(\pi-z_{i}\right)$, then $z_{i}$ is the minimum expected share, any offer poorer than $z_{i}$ is unacceptable. Similarly, $z_{j}$ is the minimum expected share of $j$. Under the assumption of linear utility function, the payoff coordinates $\left(z_{i}, z_{j}\right)$ is the point in which the negotiation break down. $\left(z_{i}, z_{j}\right)$ is the minimum payoffs for each party, thus any agreement can't be reached worse than $\left(z_{i}, z_{j}\right)$. In another word, the payoff must be adequate to compensate for losses.

\section{Modification of Subjective Probability of Breakdown}

As for $i$, the risks of breakdown can be seen from two aspects. On the one hand, it means the potential that $i$ itself drop out of the negotiation. In another hand, it means the potential that the counterparty $j$ drops out of the negotiation. Similarly, for $\boldsymbol{i}$, the subjective probability of breakdown also includes two aspects. The first is $i$ itself drop out of the negotiation, denoting the probability as $\boldsymbol{P}_{i i}$. The second is the counterparty $j$ drop out of the negotiation, denoting the probability as $\boldsymbol{P}_{i i}$. Guoqi Zhang[12]argued that the most influential factor for the offer may come from the opponent $j$. He did a modification of the subjective probability and argued that it is wrong to equate the probability of breakdown to the probability of itself drop out of the negotiation and didn't reflect the relationship between the risks of breakdown and the subjective probability. It's to say that if the bargaining last, the participant $i$ thinks that the probability of breakdown is $P_{i}=P_{i j}=\lambda_{j} \Delta$ instead of Rubinstein and Muthoo's $P_{i}=P_{i i}=\lambda_{i} \Delta$.

Actually, it still requires subjective judgment to estimate the probability when there is something that will lead to a breakdown happens although the choices that whether to carry on the negotiation ( $P_{i i}=0$ )or to quit and find another partner are private information. Thus, $P_{i}=f\left(P_{i i}, P_{i j}\right)$. In this paper, we advocate a novel methods which combined ideas of Rubinstein,Muthoo and Guoqi Zhang are as follows:

$$
\text { Eq.4 } P_{i}=\alpha P_{i i}+(1-\alpha) P_{i j}
$$

Therefore $P_{i i}=\lambda_{i} \Delta, P_{i j}=\lambda_{j} \Delta$, denoting the dependent degree of subjective probability as $\alpha$,to measure the dependence degree of our own subjective probability of breakdown. The larger the $\alpha$ is, the more dependent of previous experiences. For example, the participant $i$ has experienced many times breakdown before this negotiation, then correspondingly $\alpha$ increases and so do risks of breakdown $P_{i}$. When $\alpha=1, P_{i}$ 's form belongs to Rubinstein and Muthoo; when $\alpha=0, P_{i}$ 's form belongs to Guoqi Zhang's.

\section{Stalemate under Risks of Breakdown}

Stalemate point is the available payoff coordinates when two participants disagree with the offer of each other. The stalemate point of a bargaining model under risks of breakdown is amount to the 
node of breakdown. Define $\left(I_{i}, I_{j}\right)$ is present stalemate point, then $\left(I_{i}, I_{j}\right)=\left(z_{i}, z_{j}\right)$. The payoff of participant $i$ :

$$
\text { Eq.5 } P_{i} z_{i} \sum_{t=0}^{\infty}\left(1-P_{i}\right)^{t} \delta_{i}^{t}
$$

$P_{i}=\lambda_{j} \Delta$. When $\Delta \rightarrow 0$, e.g. there is no delay, the stalemate point of the bargaining is:

$$
\text { Eq.6 }\left(I_{i}, I_{j}\right)=\left(\frac{\lambda_{j} z_{i}}{r_{i}+\lambda_{j}}, \frac{\lambda_{i} z_{j}}{r_{j}+\lambda_{i}}\right)
$$

\section{The Utility Function of the Participant is the VNM Utility Function}

\section{Mechanism Design}

In a negotiation of commodity, the respective discount factors of buyer $\boldsymbol{i}$ and seller $j$ are: $r_{i}$ and $r_{j}$. Expected technology payoffs' net present value is $R$, the R\&D research cost is $C$, the deal price of technology is $\boldsymbol{P}$. In the process of negotiation between the buyer and the seller, both parties spread the information of purchase and the technology for sell. Besides, the bottom lines of the price are $P_{i}^{R}$ and $P_{j}^{R}$, and the process submits to independent Poisson distribution which parameter are $\lambda_{i}$. $\lambda_{i}$ represent the quantity of buyer which is willing to have a negotiation with $j$ and will accept the price $P_{i}^{R}$.similarly, $\lambda_{j}$ represent the quantity of buyer which is willing to have a negotiation with $i$ and will accept the price $P_{j}^{R}$.there are two kinds of result in a product negotiation: breakdown or last.

Two kinds of result are defined come into force after any offer been rejected by any party at any time $\boldsymbol{t} \boldsymbol{\Delta}$. The breakdown comprises three scenarios: Case one, different seller's contact with $\boldsymbol{i}$ and have a negotiation. Different buyers contact with $j$ and have a negotiation. The probability of these things happening is $P_{i} P_{j}$. Case two, different seller's contact with ${ }^{i}$ and have a negotiation with the probability $P_{j}\left(1-P_{i}\right)$. Case three, different sellers contact with $j$ and have a negotiation with the probability $\left(1-P_{j}\right) P_{i}$. All these situations will lead to breakdown due to external competition. The probability of negotiation last is $\left(1-P_{i}\right)\left(1-P_{j}\right)$. The negotiation proceeds to time $(t+1) \Delta$, if the negotiation continues and finally reaches an agreement. When the stalemate point is as follows:

$$
\text { Eq.7 }\left(I_{i}, I_{j}\right)=\left(\frac{\lambda_{j} z_{i}}{r_{i}+\lambda_{j}}, \frac{\lambda_{i} z_{j}}{r_{j}+\lambda_{i}}\right)
$$

There is no difference between acceptance and rejection in equilibrium.

In the equilibrium: $\lim _{\Delta \rightarrow 0} P_{j}^{e}=P^{*}, \lim _{\Delta \rightarrow 0} P_{i}^{e}=P^{*}$, the purchase price satisfies: $P=P^{*}$.

We can obtain the only SPNE in the bargaining model with risks of breakdown and discounting factors from the proof:

$$
\text { Eq.8 } R-P^{*}=I_{j}+\frac{r_{j}+(1-\alpha) \lambda_{j}}{\lambda+r_{i}+r_{j}}\left(R-C-I_{i}-I_{j}\right)
$$

The payments in equilibrium of the seller are: 


$$
\text { Eq.9 } P^{*}=I_{i}+\frac{r_{i}+\alpha \lambda_{i}}{\lambda+r_{i}+r_{j}}\left(R-C-I_{i}-I_{j}\right)
$$

And $\lambda=\alpha \lambda_{i}+(1-\alpha) \lambda_{j}$.

\section{The Application of Equilibrium in Import and Export of China}

China sometimes has a poor performance on the import and export business, because China has been enslaved to some special limitations which intensifying the passiveness of China. However, the subjective probability of breakdown will increase after experiencing many times breakdown. Meanwhile, we can find that the more dependent of previous experience, the less the payoff will be. Hence, there is a typical case will demonstrate the importance of the application of equilibrium in Chinese import and export.

In 2005, there was a disputation about textiles trade among China, Europe and America. The rapid expansion of the textile's market share has aroused strong reaction of the textile industry in Europe and America. Therefore, Europe and the United States proposed an application that something must be done over China's textile exports. According to<Report of The Working Party on The Accession of China>, Europe and America set import quantity limits about China's textiles, quote 242paragraph "In the event that a WTO member believed that imports of Chinese origin of textiles and apparel products covered by the ATC as of the date the WTO Agreement entered into force, were, due to market disruption, threatening to impede the orderly development of trade in these product, such Member could request consultations with China with a view to easing or avoiding such market disruption. China agree to hold its shipment to the requesting member of textile or textile products in the category or categories to a level no greater than 7.5 percent (6 percent for wool product categories)above the amount entered during the first 12 months of the most recent 14 months preceding the month in which the request for consultations was made."

In order to solve this disputation and ensure the normal development of China's textile exports, China started negotiations with the United States and Europe. China has been very passive in the world trade given the existence of "money burning" and the previous unfavorable commitment when China jointed the World Trade Organization. Moreover, Europe and the United States were in a strong position in the negotiation, so the risks of breakdown were higher ever. The Sino-US negotiation lasted for five months with seven rounds. China - EU MOU was signed in early June, but it went to breakdown due to the customs pass problem. So the two parties had to renegotiate in November. Finally, after several negotiations this problem was settled.

\section{Conclusion and Suggestion}

\section{Conclusion}

The equilibrium payoff of each participant is an increasing function of their respective discount factor and a decreasing function of the discount factor of the counterparty. $\left(R-P^{*}\right)_{\lambda_{i}}^{\prime}>0,\left(R-P^{*}\right)_{\lambda_{j}}^{\prime}<0,\left(P^{*}\right)_{\lambda_{j}}^{\prime}>0,\left(P^{*}\right)_{\lambda_{i}}^{\prime}<0$. This conclusion is consistent with Muthoo. From the perspective of subjective belief, the subjective probability of breakdown of an optimist tends to be small in the negotiation. Therefore he or she will be more patient and the share of the whole pie will be greater.

The equilibrium price is a distribution of the total expected profit $(R-C)$. And the profit of each side must be got rid of the costs including the compensation of their respective costs of direct technology transfer, the shared $\mathrm{R} \& \mathrm{D}$ costs and the technology introduction costs. Their respective discount breakdown point and the subjective probability of breakdown of the negotiations are the necessary factors to be calculated when making a distribution of the remaining expected profits.

The dependent degree of subjective probability $\alpha$ has a positive effect on the equilibrium price $P^{*}$, which means $\left(P^{*}\right)_{\alpha}^{\prime}>0$. We can get a conclusion from this: if the seller pays more 
attention to his or her own subjective probability under the danger of breakdown, he or she will be more dependent on the previous experience and long for a bigger equilibrium price.

\section{Suggestion}

According to the second type of breakdown of Muthoo, there is a probability $\boldsymbol{P}_{j}\left(1-\boldsymbol{P}_{i}\right)$ when different sellers contact with the buyer $i$ and have a negotiation. Under this circumstance, what the seller $j$ needs to do is demonstrating the uniqueness of the products to win the edge of in the competition. Hence, the sellers should devote themselves to do two jobs. First, they should improve the quality of the product and cultivating own brands. Second, they should improve the technological content of the products, increasing inputs of $R \& D$ research, defending the independent intellectual property rights and enhancing the added value of products. As for scenario three: there is a probability $\left(1-P_{j}\right) P_{i}$ when different buyers contact with the seller $j$ and have a negotiation. Under this circumstance, what the buyer $\boldsymbol{i}$ ought to do is creating a favorable atmosphere and making an adjustment of the purchase strategy to fit in the market.

Due to China subject to the commitment to the WTO, it leads to a series of passive problems about textiles in the import and export. So the subjective judgment of Chinese about the breakdown of the negotiations is big. According to the first conclusion shows that China is compared to other countries about the subjective belief is not an optimist. Therefore, China is lack of patience and its share is smaller than the other side. This situation will result in a profitless outcome for China that the sub-game perfect equilibriums is difficult to achieve. In this regard, Chinese as a member of the WTO not only must understand and abide by the use of a set of trade rules and the standard to carry out them during the foreign trade, but also actively make full use of the power of discourse of member states to participate in the formulation of international trade rules of WTO. Besides, it is necessary for China to strengthen cooperation with other developing members. We need to form a negotiating alliance using overall advantages, and focus on the interests of the multilateral trade. At the same time, when WTO holds a meeting, China also should make positive suggestions on issues related to our own interests, make rules for ourselves, while avoiding disadvantages and occupying the active position in the negotiations.

\section{Acknowledgements}

Supported by Beijing Social Science Foundation(No.16LJC008), Organization Department of Beijing Talents Project(No. 2016000020124G021)

\section{References}

[1] A.Rubin stein,1982,Perfect Equilibrium in a Bargaining Model[J], Econometrical , page numbers from 97 to 109.

[2] Hobe H, Bolt W,2002,Credible threats in negotiations: A game theory approach. Lower, Dordrecht, Springer, 2002 edition, [2002-8-31].

[3] Christopher Avery, and Peter B.Zemsky ,1991, Bargaining with deadlines and imperfect player control, Econometrica, Volume 61, page numbers from 1313 to 1339.

[4] M.Osborne and A.Rubinstein,1990,Bargaining and Markets[M],New York: Academic Press, page numbers from 69 to 90.

[5] M.G.Coles,A.Muthoo,1998, Strategic Bargaining and Competitive Bidding in a Dynamic Market Equilibrium[J],The Review of Economic Studies, volume(65),page numbers from 235 to 260.

[6] Corominas-Bosch M, 2004, Bargaining in a network of buyers and sellers. [J], Econ Theory, volume 115(1),page numbers from 35 to 77. 
[7]A.Muthoo,2000,A Non-Technical Introduction to Bargaining Theory[J],World Economics,volume (1),page numbers from 145 to 166.

[8] Gianni De Fraja,A.Muthoo,2000,Equilibrium Partner Switching in a Bargaining Model with Asymmetric Information[J],International Economic Review, volume (41),page numbers from 849 to 870 .

[9] M.G.Coles, A.Muthoo,2003,Bargaining in a Non-Stationary Environment[J],Journal of Economic Theory,volume (109),page numbers from 70 to 89.

[10] A.Wolinsky,Matching,1987,Search and Bargaining[J],Journal of Economic Theory,volume(42)page numbers from 311 to 333.

[11] Compte O, Jehiel P,1999, When outside options force concessions to be gradual, Mimeo

[12] Zhang guoqi, 2007,Research on the bargaining model of international technology transfer price, Doctoral Dissertation of Jilin University, page numbers from 72 to 73. 